\title{
Primary Hodgkin lymphoma of the adrenal gland: Case report and literature review
}

\author{
Matthew M DeNicola, J onathan W Said, Sheeja T Pullarkat \\ Department of Pathology, University of California, Los Angeles, United States \\ Correspondence: Sheeja T Pullarkat. Address: UCLA Department of Pathology \& Laboratory Medicine, BOX 951732, \\ AL-134 CHS, Los Angeles, CA 90095-1732, United States. Email: spullarkat@mednet.ucla.edu \\ Received: December 3, 2012 \\ Accepted: February 25, 2013 \\ Online Published: March 13, 2013 \\ DOI : $10.5430 / \mathrm{jhm} . \mathrm{v3n} 1 \mathrm{p} 28$ \\ URL: http://dx.doi.org/10.5430/jhm.v3n1p28
}

\section{Abstract}

Primary adrenal gland lymphoma is an uncommon diagnosis. Even among the small group of reported cases, most cases are diffuse large B-cell lymphomas. Primary Hodgkin lymphoma of the adrenal gland has only been described once previously in the English literature. We describe the second case of primary adrenal gland Hodgkin lymphoma and review pertinent literature.

\section{Key words}

Hodgkin Lymphoma, Adrenal Gland Lymphoma, Adrenal Hodgkin, EBV, EBER

\section{I ntroduction}

Secondary involvement of the adrenal gland, though uncommon, is a known complication of non-Hodgkin lymphomas ${ }^{[1]}$. However, primary lymphoma of the adrenal gland is an exceedingly rare entity, and most primary cases have been shown to be diffuse large B-cell lymphomas ${ }^{[1,2]}$. Primary Hodgkin lymphoma of the adrenal gland has only been described once previously in English literature ${ }^{[3]}$. We describe the second case of primary adrenal gland Hodgkin lymphoma and review pertinent literature.

\section{Case presentation}

A 76 year old man presented to his physician with vague right sided chest pain. During his workup, a CT scan of the abdomen and pelvis was performed, which revealed an incidental right sided adrenal nodule measuring $2.2 \mathrm{~cm}$. The liver and kidney showed no abnormalities, and there was no clinical or radiographic evidence of significant lymphadenopathy. Initial blood work revealed normal blood counts and the patient denied any history of night sweats, fever, or weight loss (B-symptoms). Follow-up CT and MRI scans performed six months later showed a persistent adrenal mass without any change in size. At that time, a full biochemical workup was performed, including dexamethasone suppression test, plasma free metanephrines, aldosterone, and plasma renin values. All parameters were within normal limits. Given the small size of the mass and the negative biochemical workup, the decision was made to follow the patient with imaging and laboratory studies. Approximately eight months later - a total of fourteen months after the mass was initially discovered - follow-up 
CT of the abdomen and pelvis revealed the mass had doubled in size, measuring up to $4.5 \mathrm{~cm}$. A biochemical workup was repeated, including cortisol level (12.2 mcg/dL), plasma renin activity (0.65 ng/mL/h), aldosterone level (2 ng/dL), plasma free metanephrines (47 pg/mL), free normetanephrines $(146 \mathrm{pg} / \mathrm{mL})$, and total free metanephrines $(193 \mathrm{pg} / \mathrm{mL})$, all falling within normal reference limits. Due to the rapid increase in size, the patient underwent a right adrenalectomy.

On gross examination, the adrenal gland weighed 55.6 grams and measured $9.0 \mathrm{~cm} \times 5.5 \mathrm{~cm} \times 2.8 \mathrm{~cm}$. Cut sections revealed a pale-tan, nodular, septated, firm, and focally hemorrhagic tumor with a surrounding compressed rim of normal appearing adrenal tissue (see Figure 1). Histologically, the tumor was composed of a multinodular and variably cellular mass with broad intervening fibrous bands (see Figure 2A). Cellular areas demonstrated scattered large Reed-Sternberg cells with two or more nuclei, uneven chromatin distribution, and prominent macronucleoli (see Figure 2B-C). Other large cells with irregular nuclear contours, pale, bubbly chromatin, and prominent nucleoli were also seen (see Figure 2D). A background inflammatory infiltrate was evident which was composed of eosinophils, small lymphocytes, and plasma cells. Scattered mitotic figures and apoptotic bodies were present. A rim of benign adrenal gland tissue was seen at the periphery of the tumor. By immunohistochemistry, the neoplastic Hodgkin cells were positive for CD30, CD15, and Fascin, weakly positive for PAX-5, and negative for CD45 and CD20 (see Figure 3A-D). EBV EBER in situ hybridization was also positive in neoplastic cells, with a subset positive for EBV LMP (see Figure 3E). The lymphocytes in the background were predominantly CD3-positive T-cells with a smaller population of CD20-positive B-cells. Based on the histologic and immunophenotypic findings, a diagnosis of Hodgkin lymphoma, nodular sclerosis subtype was rendered.

Soon after the surgery, the patient relocated out of state and was lost to follow up at our institution. Additional details regarding further therapy or prognosis is thus not available at this time.

Figure 1. Gross photograph of a cut section of the adrenal gland demonstrating a large, multinodular tumor surrounded by a thin rim of uninvolved adrenal gland tissue (scale shown).

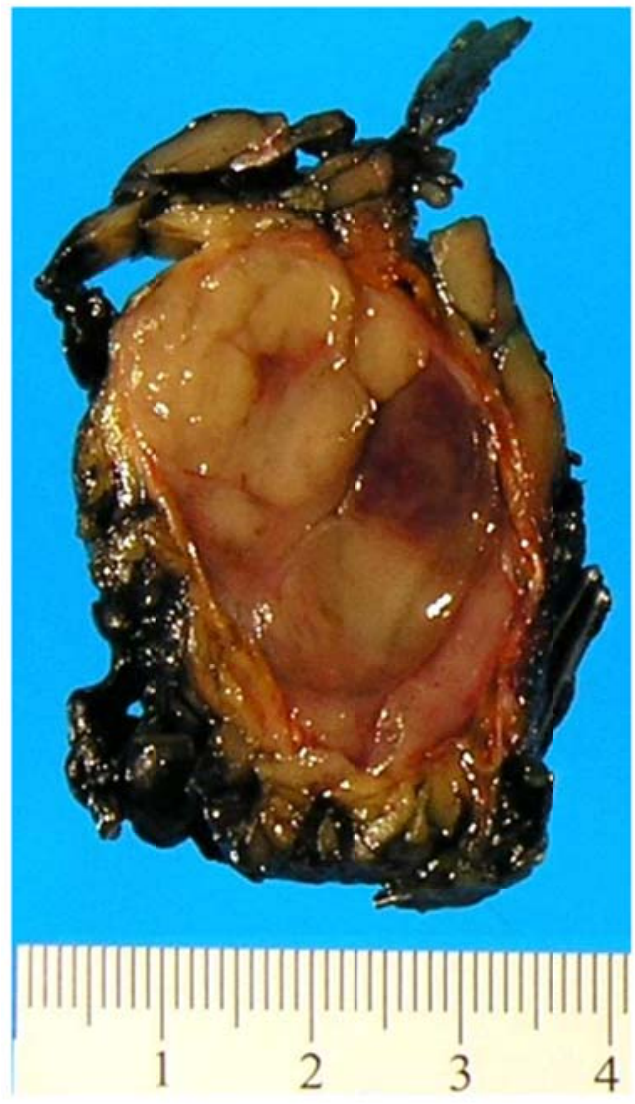



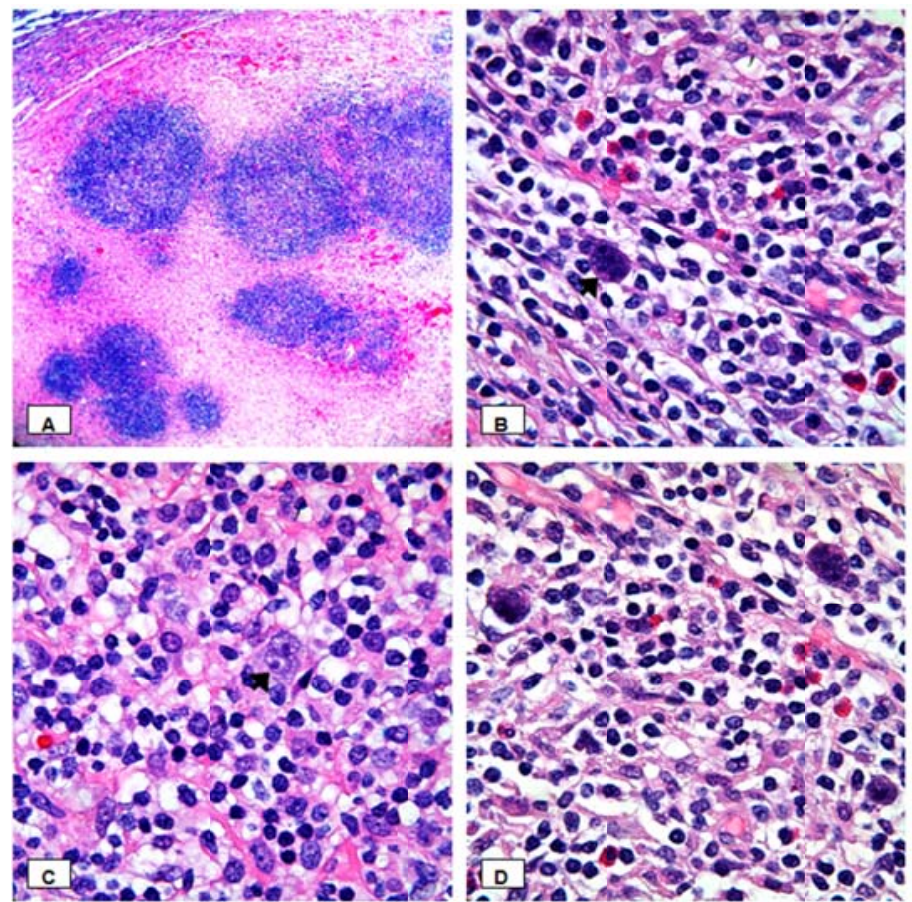

Figure 2(A-D). A. Low power magnification (40X) showing lymphoid nodules surrounded by thick fibrous bands. B. High power magnification (1000X) showing Reed Sternberg cell (arrow) in a background containing small lymphocytes, scattered plasma cells, and eosinophils. C. High power magnification (1000X) showing another Reed Sternberg cell (arrow). D. Additional high power magnification (1000X) showing other large atypical cells in a mixed inflammatory background.
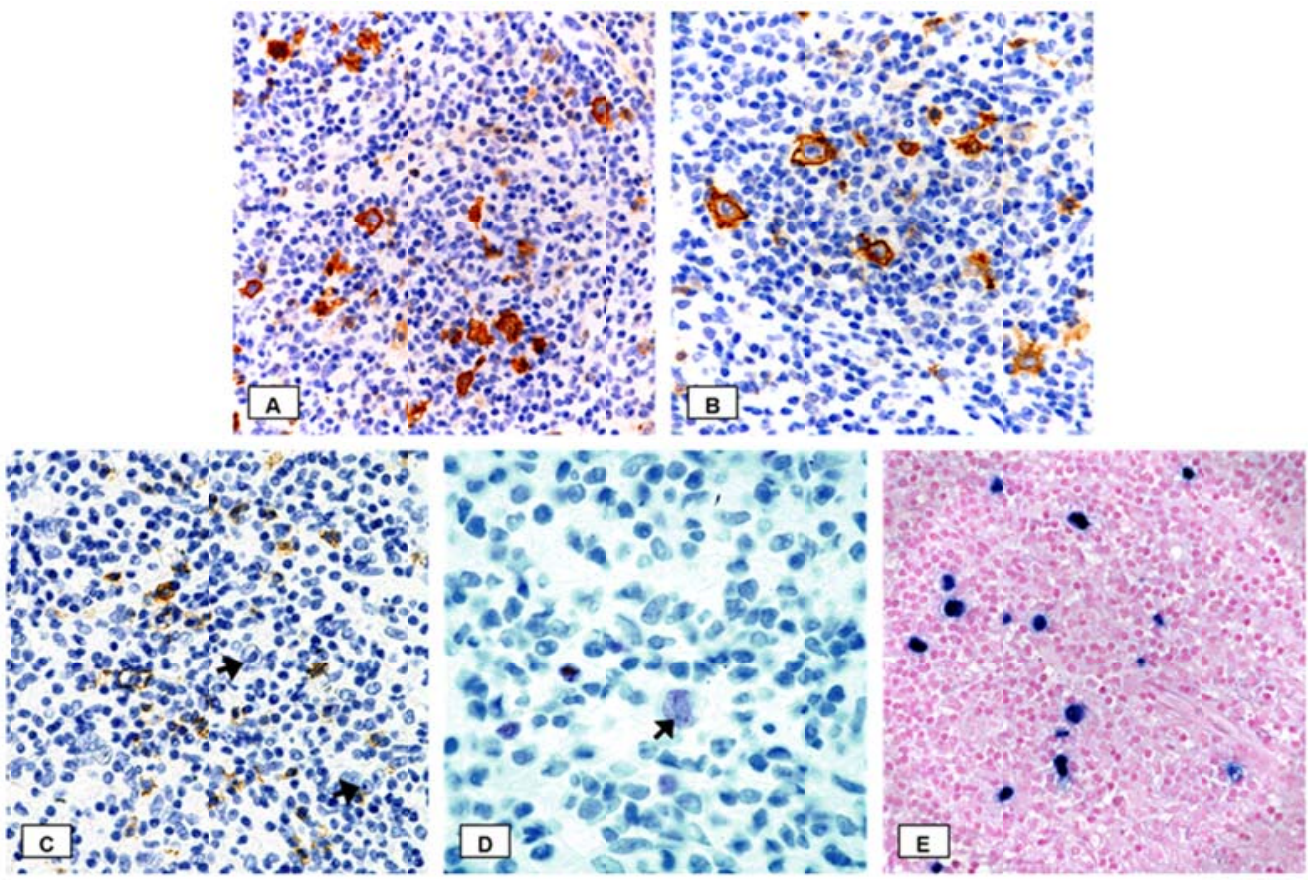

Figure 3(A-E). A. CD15 immunostain (400X) showing strong expression by the Reed Sternberg cells. B. CD30 immunostain (400X) shows similar findings. C-D. CD20 immunostain (C, 400X) is negative in neoplastic cells (arrows), while PAX5 (D, 1000X) shows weak positivity. E. EBV-EBER in-situ hybridization (400X) shows Reed Sternberg cells with strong nuclear staining. 


\section{Discussion}

Primary lymphomatous involvement of the adrenal gland is extremely rare, accounting for $<1 \%$ of all non-Hodgkin lymphoma ${ }^{[1,2]}$. Literature regarding primary adrenal lymphoma consists mostly of case reports and small series ${ }^{[1,5-7]}$. Among the primary adrenal gland lymphomas, most cases have been shown to be diffuse large B-cell lymphoma, with only rare cases of plasmablastic lymphoma and extranodal NK/T-cell lymphoma, nasal type, described ${ }^{[1]}$. A comparison between all reported cases of primary adrenal lymphomas and the two known cases of primary adrenal Hodgkin lymphoma (including the current case) has been illustrated in Table 1. Briefly, the cases of primary adrenal non-Hodgkin lymphomas are bilateral in more than 50\% of cases, with mean tumor size ranging from 7.25-8.5 cm, and are positive for EBV infection in less than half of the cases. Adrenal gland insufficiency was seen in 10\%-50\% of cases, depending on series. In contrast, both the cases of primary adrenal gland Hodgkin lymphoma were unilateral, with tumor size averaging $5.5 \mathrm{~cm}$, and 100\% EBV positivity, with no evidence of adrenal insufficiency.

Table 1. Primary Adrenal Hodgkin Lymphomas compared to Primary Adrenal Lymphomas of all types

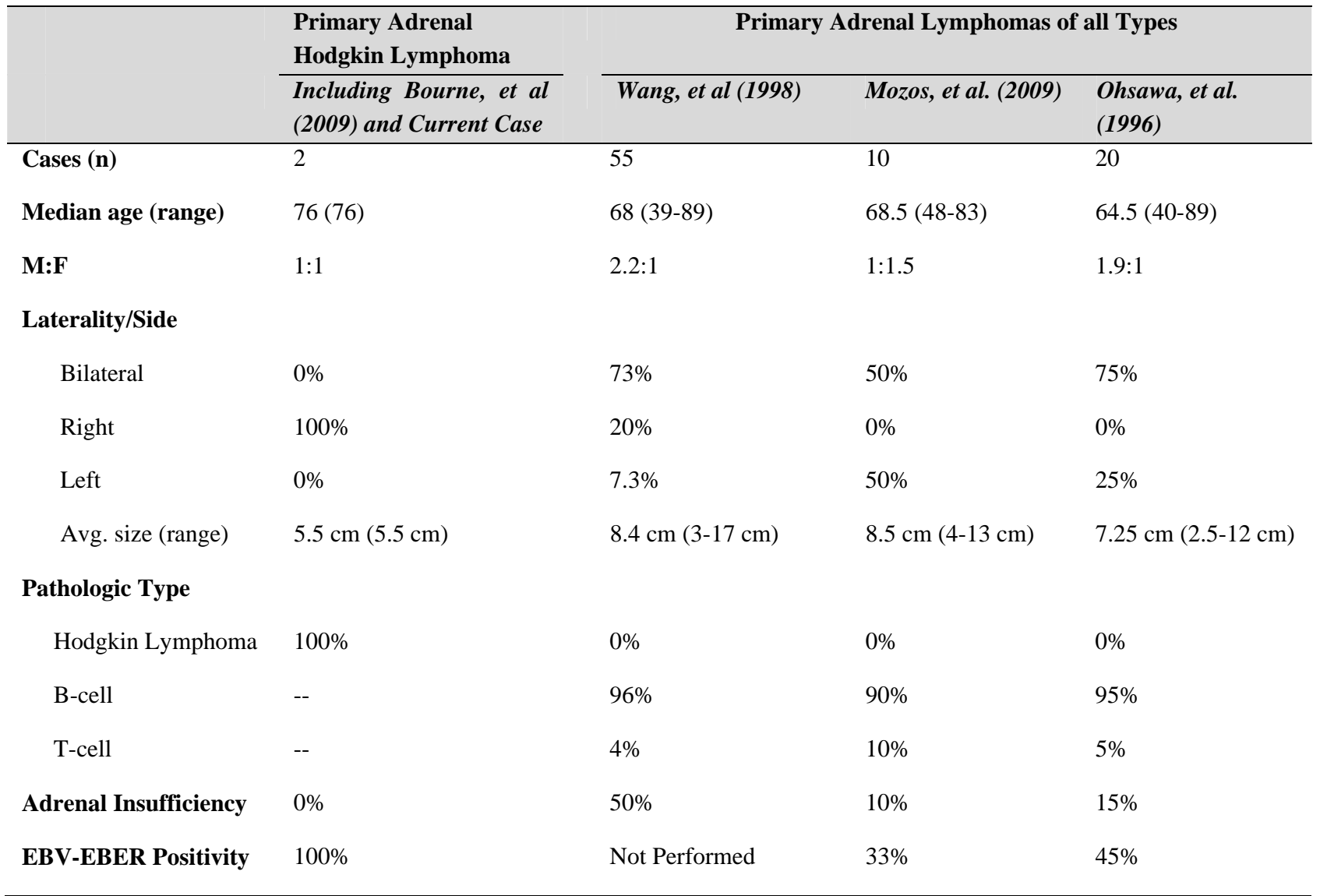

To compound the rarity of the current case, this is an atypical presentation for any Hodgkin lymphoma of any site in respect to patient demographics and pathologic subtype. Our case involves a 76 year old man, while nodular sclerosis Hodgkin lymphoma is generally seen in younger patients, with a peak age between $15-34$ years ${ }^{[8]}$. Additionally, our case was positive for EBV EBER. EBV positivity is most commonly associated with the mixed cellularity type of Hodgkin lymphoma, with up to 75\% of mixed cellularity Hodgkin lymphoma cases reported as positive for EBV. Nodular sclerosis Hodgkin lymphoma, on the other hand, is typically EBV negative, with $<20 \%$ of cases showing EBV positivity. The unilateral gland involvement in our case is also atypical with respect to other cases of primary adrenal lymphomas of any type, which present with bilateral involvement in $60 \%-80 \%$ of cases ${ }^{[4,6]}$. Thus, this case is unique both in the rarity of the diagnosis itself, and also with regards to the atypical features of age, subtype, EBV positivity, and clinical presentation. 
Interestingly, the only other reported case of primary adrenal Hodgkin lymphoma, as described by Bourne, shares the same atypical features as the current case ${ }^{[2]}$. A comparison of these two cases is illustrated in Table 2. Patient age, tumor size, and laterality are remarkably similar. In addition, neither patient experienced B-symptoms. This is unusual when compared to primary nodal Hodgkin Lymphoma, which is almost always accompanied by B-symptoms. Also of note, neither patient experienced adrenal insufficiency, a symptom reported in up to $50 \%$ of primary adrenal non-Hodgkin lymphomas. The only notable difference in the two cases is patient sex. Based on these limited cases, primary adrenal Hodgkin lymphoma may be more likely to present in older patients, with unilateral distribution, and show equal sex distribution. However, given the rarity of this diagnosis, no definitive demographic conclusions can be drawn.

How primary lymphomas arise in the adrenal gland has not been clearly elucidated. One of the proposed theories has suggested that prior episodes of adrenalitis, namely autoimmune adrenalitis, may have resulted in an acquired mileu that may be responsible for lymphomagenesis ${ }^{[2,10]}$. Other literature has focused on lymphoma arising from hematopoietic tissue inherent to the adrenal gland ${ }^{[2,5,11]}$. In the latter discussions, some immune dysfunction is presumed to be a predisposing factor to developing primary adrenal lymphoma ${ }^{[5,11]}$. Additionally, circulating precursor cells for Hodgkin and Reed-Sternberg cells have been postulated as potential causes of primary extranodal Hodgkin lymphomas, and could feasibly deposit in the adrenal gland causing primary adrenal Hodgkin lymphoma ${ }^{[12]}$.

Table 2. Comparison of Current Case with Case Described by Bourne, et al (2009)

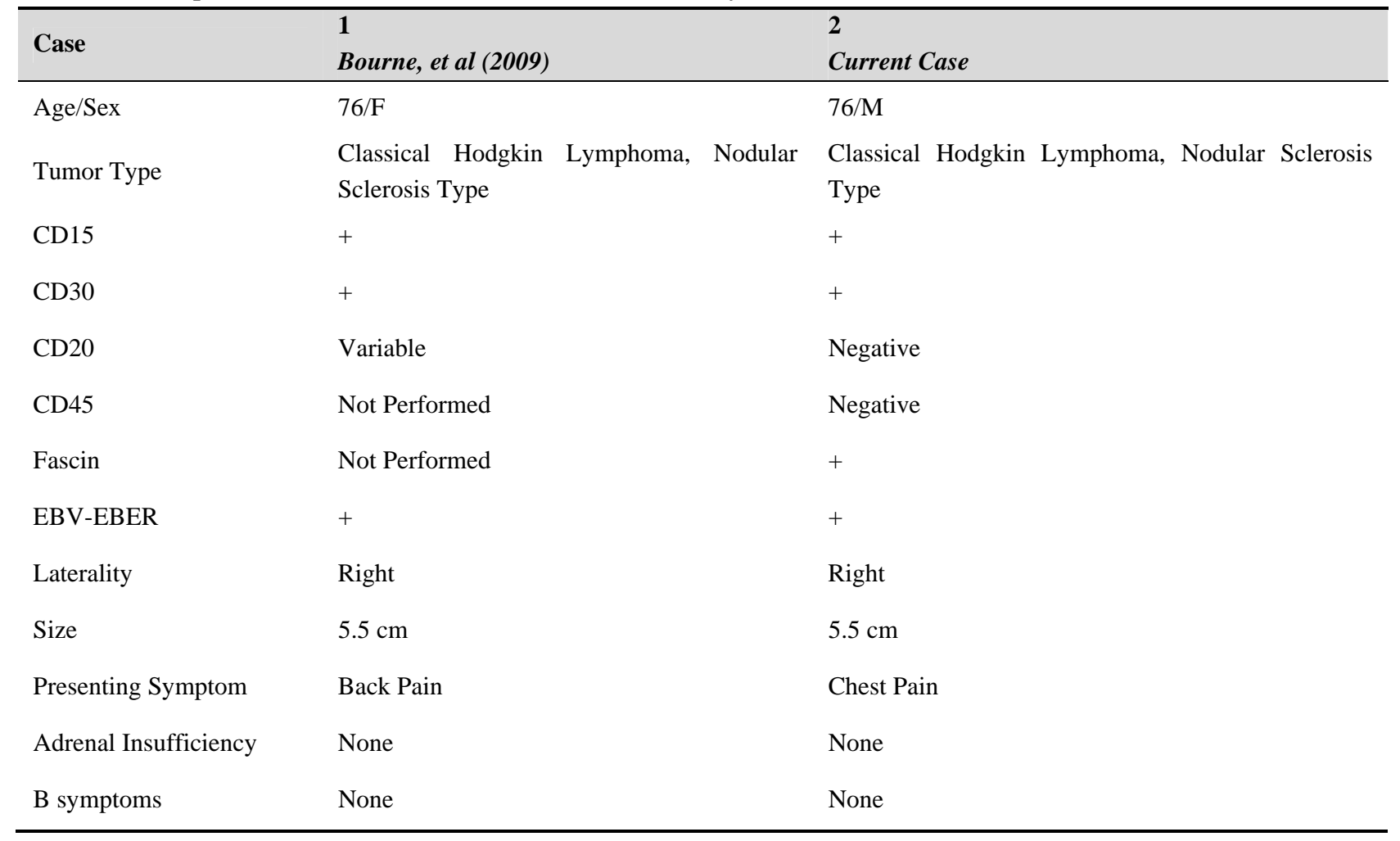

The malignant transformative abilities of EBV are well documented in both epithelial and lymphoid cells. The relationship of EBV and Hodgkin lymphoma has been the subject of robust research in recent years. This research has resulted in an increased understanding of the prominent and causative role that EBV likely plays in certain subtypes of Hodgkin lymphoma ${ }^{[9]}$. Excellent reviews of this topic are available elsewhere in the literature, and will not be expanded upon here ${ }^{[9,13]}$. In relation to this discussion, EBV positivity has been reported in a high percentage of primary adrenal lymphomas of any kind, ranging from $33-45 \%$ in two modest sized series (see Table 1$)^{[1,14]}$. With the addition of this case to the literature, EBV positivity is now also seen in both known cases (100\%) of primary adrenal Hodgkin lymphoma. As mentioned above, nodular sclerosis Hodgkin lymphoma cases are typically EBV-negative, making the presence of EBV 
positivity in both cases of primary adrenal nodular sclerosis Hodgkin lymphoma noteworthy. This is especially interesting if considered together with the aforementioned notion of immune dysfunction as a predisposing factor for primary adrenal lymphoma. Variable immune responses to an EBV infection are linked to the development of EBV-positive lymphoma, including EBV-positive Hodgkin lymphoma ${ }^{[9]}$. With this in mind, the idea that this disorder is related to immune dysfunction and/or senile EBV-related lymphoproliferative disorders seems plausible.

The prognosis of primary adrenal Hodgkin lymphoma is still uncertain, as no clinical follow-up information is available for our case or the prior case described by Bourne, et al. Given the atypical features of age, subtype, EBV positivity, and clinical presentation discussed above, it seems unlikely that the prognosis of primary adrenal Hodgkin lymphoma would be similar to nodal classical Hodgkin lymphoma. Numerous studies over the years have searched for morphologic findings with prognostic significance for Hodgkin lymphoma. Such early morphologic distinctions still help frame the current classification of classical Hodgkin lymphoma into nodular sclerosis, lymphocyte-depleted, lymphocyte-rich, and mixed cellularity subtypes. More recent studies have analyzed histologic criteria, specifically for nodular sclerosis Hodgkin lymphoma, including Reed-Sternberg cell enumeration, cellular atypia, necrosis, proliferative index, as well as relative background lymphocyte and eosinophil volume ${ }^{[15]}$. Tissue eosinophilia, in particular, is advocated by some groups as a predictor of a poorer prognosis ${ }^{[16]}$. Consensus for using this data in routine grading of Hodgkin lymphoma does not exist. As our case is classified as nodular sclerosis Hodgkin disease, it may be worth noting that neither tissue eosinophilia greater than $5 \%$ nor clustering of eosinophils was noted. Further information on the eosinophil count was not recorded in the case described by Bourne, et al.

In the current case, given the age at presentation, extranodal involvement, and EBV status, EBV-positive diffuse large B-cell lymphoma (DLBCL) of the elderly may be in the differential diagnosis. This disease occurs in patients older than 50 years (mean age of 71 years) with no prior diagnosis of lymphoma ${ }^{[8]}$. In addition, EBV-positive DLBCL of the elderly may also show a mixed inflammatory background and large atypical cells morphologically similar to Hodgkin and Reed-Sternberg-like cells. The neoplastic cells are by definition EBV positive, and are variably CD30 positive. However, in EBV-positive DLBCL of the elderly, neoplastic cells are negative for CD15, and typically express strong B-cell markers CD20 and/or CD79a.

In summary, we report a unique case of primary adrenal nodular sclerosis Hodgkin Lymphoma. This case reiterates the importance of including primary adrenal lymphoma in the differential diagnosis of a retroperitoneal or a suprarenal mass for prompt diagnosis leading to early intervention and treatment.

\section{Conflict of interests/ disclosures}

The authors declare that they have no conflict of interest.

\section{References}

[1] Mozos A, Ye H, Chuang W-Y, et al. Most primary adrenal lymphomas are diffuse large B-cell lymphomas with non-germinal center B-cell phenotype, BCL6 gene rearrangement and poor prognosis. Mod Pathol. Sep 2009; 22(9):1210-1217. PMid:19525926 http://dx.doi.org/10.1038/modpathol.2009.87

[2] Spyroglou A, Schneider HJ, Mussack T, Reincke M, won Werder K, Beuschlein F. Primary Adrenal Lymphoma: 3 Case reports with Different Outcomes. Exp Clin Endocrinol Diabetes. 2011; 119:208-213. PMid:21374545 http://dx.doi.org/10.1055/s-0031-1271629

[3] Bourne AE, Bell SW, Wayment RO, Schwartz BF. Primary Hodgkin lymphoma of the adrenal gland: a unique case presentation. Can J Urol. Jun 2009; 16(3):4694-4696. PMid:19497184

[4] Kumar R, Xiu Y, Mavi A, El-Haddad G, Zhuang H, Alavi A. FDG-PET imaging in primary bilateral adrenal lymphoma: a case report and review of literature. Clin Nucl Med. 2005; 30(4):222-230. PMid:15764875

http://dx.doi.org/10.1097/01.rlu.0000155983.46815.1c 
[5] Grigg AP, Connors JM. Primary adrenal lymphoma. Clin Lymphoma. 2003; 4:154-160. http://dx.doi.org/10.3816/CLM.2003.n.024

[6] Singh D, Kumar L, Sharma A, et al. Adrenal involvement in non-Hodgkin's lymphoma: four cases and review of literature. Leuk Lymphoma. 2004; 45:789-794. PMid:15160957 http://dx.doi.org/10.1080/10428190310001615756

[7] Schreiber CS, Sakon JR, Simiao FP, et al. Primary adrenal lymphoma: a case series study. Ann Hematol. 2008; 87:859-861. PMid:18458904 http://dx.doi.org/10.1007/s00277-008-0492-x

[8] Swerdlow SH, Campo E, et al, eds. WHO Classification of Tumors of Haematopoietic and Lymphoid Tissues. 4th ed. Lyon: IARC; 2008.

[9] Massini G, Siermer D, Hohaus S. EBV in Hodgkin Lymphoma. Medit J Hemat Infect Dis. 2009; 1(2):e2009013.

[10] Ozimek A, Diebold J, Linke R, et al. Bilateral primary adrenal non-Hodgkin’s lymphoma and primary adrenocortical carcinoma review of the literature preoperative differentiation of adrenal tumors. Endocr J. 2008; 55:625-638. PMid:18490838 http://dx.doi.org/10.1507/endocrj.K08E-035

[11] Wang J, Sun NC, Renslo R, et al. Clinically silent primary adrenal lymphoma: a case report and review of the literature. Am J Hematol. 1998; 58:130-136. http://dx.doi.org/10.1002/(SICI)1096-8652(199806)58:2<130::AID-AJH8>3.0.CO;2-T

[12] Jones RJ, Gocke GC, Kasamon YL, et al. Circulating clonotypic B cells in classic Hodgkin lymphoma. Blood. 2009 Jun 4; 113(23):5920-6. PMid:19188663 http://dx.doi.org/10.1182/blood-2008-11-189688

[13] Anderson J. Epstein-Barr virus and Hodgkin’s lymphoma. Herpes. May 2006; 13(1):12-16.

[14] Ohsawa M, Tomita Y, Hashimoto M, Yasunaga Y, Kanno H, Aozasa K. Malignant lymphoma of the adrenal gland: Its possible correlation with the Epstein-Barr virus. Mod Pathol. May 1996; 9(5):534-543. PMid:8733769

[15] Von Wasielewski S, Franklin J, Fischer R, et al. Nodular Sclerosing Hodgkin disease: new grading predicts prognosis in intermediate and advanced stages. Blood. 2003 May 15; 101(10):4063-9. PMid:12543871 http://dx.doi.org/10.1182/blood-2002-05-1548

[16] Von Wasielewski S, Seth S, Franklin J, et al. Tissue eosinophilia correlates strongly with poor prognsis in nodular sclerosing Hodgkin’s disease, allowing for known prognostic factors. Blood. 2000 Feb 15; 95(4):1207-13. PMid:10666192

[17] Oyama T, Ichimura K, Suzuki R, et al. Senile EBV+ B-cell lymphoproliferative disorders: a clinicopathologic study of 22 patients. Am J Surg Pathol. 2003; 27(1):16-26. PMid:12502924 http://dx.doi.org/10.1097/00000478-200301000-00003

[18] Ouansafi I, Bell S, Jaffe E. Adrenal Hodgkin Lymphoma. Br J Haematol. Feb 2010; 148(3):341. PMid:19563514 http://dx.doi.org/10.1111/j.1365-2141.2009.07776.x 